\title{
Cover Crop Management in a Sauvignon Blanc/Ramsey Vineyard in the Semi-Arid Olifants River Valley, South Africa. 2. Effect of Different Cover Crops and Cover Crop Management Practices on Grapevine Performance
}

\author{
J. C. Fourie ${ }^{1 *}$, P.J.E. Louw $^{1 * *}$ and G.A. Agenbag ${ }^{2}$
}

(1) ARC Infruitec-Nietvoorbij, Private Bag X5026, Stellenbosch, 7599 Republic of South Africa

(2) Department of Agronomy, University of Stellenbosch, Stellenbosch, 7600 Republic of South Africa

Submitted for publication: January 2007

Accepted for publication: July 2007

Key words: Cover crops, soil management, grapevines, grape yield, shoot growth, grape juice.

\begin{abstract}
The trial was conducted over a period of ten years (1993/94 to 2002/03) on a sandy soil in a Sauvignon blanc/ Ramsey vineyard near Lutzville (31'35'S, $\left.1^{\circ} 52^{\prime} \mathrm{E}\right)$, situated in the semi-arid Olifants River Valley of the Western Cape. Fourteen treatments, consisting of three grain species and four legumes, managed according to two cover crop management practices, were included. One management practice consisted of cover crops which were sown annually and full surface, post-emergence chemical control which was applied before bud break and when the berries reached pea size (BB). The second management practice consisted of cover crops which were sown biennially. Post-emergence chemical control was applied to the vine row before bud break and full surface when the berries reached pea size (AB). From 1999/2000 to 2002/03 the cover crops were sown annually, while the full surface post-emergence control applied at the end of November was advanced to mid-October. Two treatments in which Avena sativa L. v. Saia ('Saia' oats) and Vicia dasycarpa Ten. (grazing vetch) were sown annually, controlled mechanically in the work row and chemically in the vine row from bud break to harvest (MC), were also applied. These treatments were compared to a control, in which no cover crop was sown and MC was applied. A treatment in which no cover crop was sown and BB was applied (weedchem), was also included. During the third growing season of the vines (1994/95), the grapevine shoot mass of the BB treatments of grazing vetch and Medicago truncatula Gaertn. v. Paraggio ('Paraggio' medic) was significantly more than that of the $\mathrm{AB}$ and $\mathrm{MC}$ treatments, with the exception of Secale cereale $\mathrm{L}$. $\mathrm{v}$. Henog (AB) and grazing vetch (MC). The first harvest (1994/95) from the grapevines in the BB treatments was significantly higher than that of weedchem and the MC treatments. The grape yield of the BB treatments, grazing vetch (AB) and Ornithopus sativus L. v. Emena (pink Seradella) (AB) was significantly more than that of weedchem and the control during the $1997 / 98$ season. The $\mathrm{NO}_{3}-\mathrm{N}$ concentration in the leaf petioles in all the cover crop treatments was, with the exception of the AB treatments of rye, M. truncatula Gaertn. v. Parabinga ('Parabinga' medic) and grazing vetch, significantly higher than that in weedchem and the control, as measured during the 1994/95 season. The $\mathrm{NO}_{3}-\mathrm{N}$ concentration in the leaf petioles of the $B B$ and $A B$ treatment of a species differed significantly. The $N$ concentration in the juice of the cover crop treatments during the $1995 / 96$ season was, with the exception of 'Saia' oats (MC) and 'Parabinga' medic (AB), significantly higher than that of weedchem and the control. During the 1998/99 season, the $N$ concentration of the juice in the BB and AB treatments of grazing vetch and pink Seradella was significantly higher than that of the MC treatments, two rye treatments, weedchem and the AB treatments of the other cover crops. The concentration of $\mathrm{Ca}$ in the juice of the cover crop treatments was, with the exception of the pink Seradella treatments, significantly higher than that of weedchem and the control. Wine quality did not differ between treatments.
\end{abstract}

Cover crops are used as a non-specific method for the pre-emergence control of both winter and summer growing weeds in vineyards (Van Huyssteen et al., 1984; Fourie et al., 2001, 2005 \& 2006). The effective management of this biological method of weed control as an alternative to chemical weed control is of the utmost importance, because an increasing number of weed species are developing resistance towards herbicides (Anonymous, 1997; Henkes, 1997). Cover crop mulches facilitate a reduction in water runoff and erosion (Louw \& Bennie, 1992) and reduce temperature fluctuations in the soil (Van Huyssteen et al., 1984).
They also restrict evaporation from the soil surface (Van Huyssteen et al., 1984), thereby conserving soil water (Buckerfield \& Webster, 1996).

Van Huyssteen \& Weber (1980) and Fourie et al. (2006) observed that grape production and pruning mass were affected significantly by the soil cultivation practice applied to the medium textured soils of a non-irrigated and irrigated vineyard, respectively. The use of a permanent growing cover (weeds or cover crop) in the work row has been shown to reduce grapevine vigour (Van Huyssteen \& Weber, 1980; Soyer et al., 1984; Lombard et

*Corresponding author: E-mail address: FourieJ@arc.agric.za

**Present address: Sapex Exports, 11 Victoria Street, Stellenbosch, 7599 Republic of South Africa.

Acknowledgements: The authors thank the ARC and Winetech for financial support, as well as the staff of the Soil Science Section of ARC Infruitec-Nietvoorbij for technical support. This study is part of a PhD (Agric) dissertation at the University of Stellenbosch. 
al., 1988; Pool et al., 1990; Sicher et al., 1995; Pinamonti et al., 1996; Ingels et al., 2005) and yield (Van Huyssteen \& Weber, 1980; Soyer et al., 1984; Lombard et al., 1988; Sicher et al., 1995; Pinamonti et al., 1996) compared to grapevines grown under other soil cultivation practices. Ingels et al. (2005) observed that a permanent grass cover reduced grapevine vigour compared to a vineyard in which a permanent mixed clover cover was used. According to Pool et al. (1990) and Ingels et al. (2005), grape yield was not affected by the soil cultivation practice applied, while Anonymous (1984) reported higher yields for grapevines with a permanent cover crop in comparison with grapevines in which other soil cultivation practices were applied. Grape yield under winter growing cover crops controlled chemically before bud break was significantly higher than that of grapevines in which clean cultivation was applied (Buckerfield \& Webster, 1996; Fourie et al., 2006). Fourie et al. (2006) indicated that the performance of full bearing irrigated grapevines established on a medium textured soil, in which annual cover crops were allowed to grow in the work row until the vines reached the berry set stage, was similar to that of grapevines in which no cover crops were sown and the weeds were controlled mechanically or chemically from bud break to harvest.

A permanent grass cover crop significantly decreased the $\mathrm{N}$ concentration in grapevine leaves compared to that of vines in which full surface chemical control was applied to a bare soil (Soyer et al., 1984; Lombard et al., 1988; Tan \& Crabtree, 1990; Sicher et al., 1995; Pinamonti et al., 1996). Ingels et al. (2005) observed a higher grapevine petiole $\mathrm{N}$ where a cover crop mix was disked in during early spring in comparison with a vineyard in which weeds were disked in or cover crops were slashed. Nfixing species should, however, not be used as cover crops over the long-term on a medium textured soil, because they may lead to an early season over-supply of $\mathrm{N}$ which could cause vigorous grapevine growth (Fourie et al., 2006).

According to Lombard et al. (1988) and Ingels et al. (2005), soil cultivation did not affect the soluble solids content and acidity of grape juice at harvest. Van Huyssteen (1990) and Fourie et al. (2006), however, reported significant differences in total titratable acids of grapevine juice between soil cultivation treatments, which was probably caused by differences in crop size (Fourie et al., 2006) and vegetative growth (Conradie, 2001b; Fourie et al., 2006). A permanent green cover in the work row competed with the grapevines for nutrients during the growing season, which resulted in the must being either low in ammonium-N (Dupuch, 1997) or N deficient (Van Huyssteen, 1990). This increased the time necessary to ferment all the sugar in the must (Dupuch, 1997) or caused stuck fermentation to occur (Van Huyssteen, 1990). According to Maigre (1997), a permanent grass cover in the work row had a negative effect on wine quality during years when the competition between the grass and the grapevines was high. Wine quality was, however, not affected negatively where annual cover crops were sown and full surface post-emergence chemical weed control was applied when the berries reached pea size (Fourie et al., 2006).

The reviewed literature indicated that soil cultivation practices impacted significantly on grapevine performance. The effect of annual cover crops controlled chemically during different stages of the grapevine growing season on the performance of both young and fully grown grapevines established on a medium textured soil in the Coastal region was determined (Fourie et al., 2006). Cover crop growth and $\mathrm{N}$ contributed by them depend on species, length of growing season, climate and soil conditions (Shennan, 1992). The effect of different cover crop management practices on the performance of grapevines established on a sandy soil in a semiarid grapevine region should, therefore, also be clarified. This study was conducted to determine the effect of different cover crop management practices applied to three grain and four $\mathrm{N}$ fixing cover crop species on the performance of Sauvignon blanc/ Ramsey vines established on a sandy soil. The objective was to supply guidelines for sustainable cover crop management in vineyards on these soils in the Olifants River Valley.

\section{MATERIALS AND METHODS}

\section{Experiment vineyard and layout}

The detailed experimental procedures and layout have already been described in Fourie et al. (2005). The trial was conducted in a Sauvignon blanc/Ramsey vineyard trained on a hedge trellis system (Archer \& Booysen, 1987) and established on a sandy soil (98.6\% sand) at the Nietvoorbij research farm near Lutzville (313' S, 18 $52^{\circ}$ 'E). During winter (April to August) irrigation was scheduled as described by Fourie et al. (2005). During summer the soil water matric potential was measured by means of 11 sets of mercury manometer tensiometers, installed on the vine row at depths of $300 \mathrm{~mm}, 600 \mathrm{~mm}$ and $900 \mathrm{~mm}$. Soil water retention curves and drainage curves, determined by Conradie \& Myburgh (2000) for a similar soil adjacent to the trial site, were used to convert matric potential to soil water content. Field capacity was estimated at the point where the drainage rate began to decrease. Weekly tensiometer readings, taken before irrigation, were used to calculate the amount of water needed to restore the soil to field water capacity. The required amount of water was applied weekly from bud break (first week of September) to harvest (first week of February). The grapevines received $30 \mathrm{~kg} \mathrm{P} / \mathrm{ha}$ at the end of February (just before seedbed preparation), $30 \mathrm{~kg} \mathrm{~K} /$ ha and $14 \mathrm{~kg} \mathrm{~N} /$ ha during the second week of April (just after the cover crops were sown). At the two-to-four-leaf stages of the grass cover crops $28 \mathrm{~kg} \mathrm{~N} /$ ha was applied. Two weeks after bud break (late September), $30 \mathrm{~kg} \mathrm{~K} / \mathrm{ha}$ and $42 \mathrm{~kg} \mathrm{~N} /$ ha were applied. The vines were spur pruned according to vigour and were suckered a few weeks after bud break. Shoot positioning was done and the vines tipped and topped as soon as the canes grew more than $100 \mathrm{~mm}$ past the highest line of the trellis system (approximately $1.1 \mathrm{~m}$ above the cordon of the vine).

Eighteen treatments are reported on with respect to grapevine performance (Table 1). An additional five treatments were applied but considered as not pertinent to the present trial. Two cover crop management practices were applied to seven cover crop species. One cover crop management practice consisted of cover crops being sown annually and full surface post-emergence chemical control being applied before bud break and when the berries reached pea size, i.e. end of November (BB). The other cover crop management practice consisted of the cover crops being sown biennially and post-emergence chemical control being applied to the vine row before bud break and full surface when the berries reached pea size (AB). From 1999/2000 to 2002/03 the cover crops in the $\mathrm{AB}$ treatments were sown annually and the full surface postemergence chemical control applied end of November was advanced to mid-October, since the species have proved unable to 
re-establish successfully in previous seasons (Fourie et al., 2005). Two treatments in which Avena strigosa L. v. Saia ('Saia' oats) and Vicia dasycarpa Ten. (grazing vetch) were sown annually and controlled mechanically in the working row and chemically in the vine row from before bud break to harvest (MC), were also applied. The cover crop treatments were compared to a control treatment, in which no cover crop was sown and MC was applied. A treatment in which no cover crop was sown and full surface post-emergence chemical weed control was applied from before bud break to harvest (weedchem), was also included.

\section{Statistical procedures}

Twenty three treatments were randomly allocated within each of three blocks. The treatment design was an $(8 \times 2)+7$ factorial with factors eight cover crops, two management practices, as well as seven other practices. The experiment was repeated for 10 consecutive seasons (years). The size of each unit (plot) was $108 \mathrm{~m}^{2}$. Eight experimental grapevines per plot were used for measurements. Individual plots were separated by one border grapevine row and five border grapevines within rows. Analyses of variance were performed for each season separately, using SAS (SAS, 1990). Student's $t$ least significant difference (LSD) values were calculated at a 5\% significance level to facilitate comparison between treatment means. The Shapiro-Wilk test was performed to test for non-normality (Shapiro \& Wilk, 1965).

\section{Measurements}

\section{Shoot mass and grape yield}

Shoot mass and grape yield were measured for ten seasons (1993/94 to 2002/03) and nine seasons (1994/95 to 2002/03), respectively. All treatments were harvested on the same date.

\section{Berry weight and volume}

Berry weight and volume were determined during 1997/98 and $2002 / 03$. One hundred berries were picked randomly from approximately 10 bunches for each treatment plot during harvest. The berries were weighed and their volume determined volumetrically.

\section{Leaf petiole analysis.}

Petiole analyses were carried out over nine seasons (1994/95 to 2002/03). Leaf petioles were collected at full bloom from locations directly opposite clusters. Leaves and petioles were separated immediately after sampling. Petiole samples were extracted with $1.0 \mathrm{M} \mathrm{KCl}$ and analysed colorimetrically for $\mathrm{NO}_{3}-\mathrm{N}$ (The Non-affiliated Soil Analysis Work Committee, 1990).

\section{Juice analysis.}

Grapes were harvested when the sugar concentration averaged $22^{\circ} \mathrm{B}$. A representative sample (approximately one bunch per experimental vine) from each plot was crushed in a hydraulic press. Free run juice was analysed for sugar content (temperature compensated Abbé refractometer), $\mathrm{pH}$ (654 Metrohm $\mathrm{pH}$ meter) and titratable acidity $(50 \mathrm{~mL}$ juice titrated with $0.333 \mathrm{M} \mathrm{NaOH}$ to $\mathrm{pH}$ 7.0 and expressed as $\mathrm{g}$ tartaric $\mathrm{acid} / \mathrm{L})$. These measurements were done for nine seasons (1994/95 to 2002/03). Total juice $\mathrm{N}$ was determined for eight consecutive years (1995/96 to 2002/03) using an automated colorimetric method (The Non-affiliated Soil Analysis Work Committee, 1990), following digestion with selenous acid/sulphuric acid. Total P, K, Ca and Mg concentrations in the juice were determined for five consecutive years (1995/96 to
1999/2000) by atomic absorption spectrophotometry, following digestion with nitric acid/perchloric acid.

\section{Experimental wines}

Experimental wines were prepared from the grapes of 13 of the 23 treatments over four consecutive seasons from 1996/97 to 1999/2000, as described by Fourie et al. (2006). The wines were stored at $14^{\circ} \mathrm{C}$ for three months before evaluation. Sensory evaluation was carried out by an experienced panel of 14 members on a nine point scorecard (Tromp \& Conradie, 1979). The wines were presented in coded form and evaluated for overall wine quality, as well as for aroma and taste.

\section{RESULTS AND DISCUSSION}

\section{Grape yield and shoot mass}

The effect of the different management practices began to manifest during the first (1993/94) season (Table 1). The shoot mass of the two year old vines (1993/94) in the BB treatment of 'Saia' oats was significantly higher than that of the $\mathrm{MC}$ and $\mathrm{AB}$ treatments. Shoot mass in the AB treatments of the two Medicago varieties and the $\mathrm{MC}$ treatment of grazing vetch was also significantly lower than that of the BB treatment of Secale cereale L. v. Henog (rye) and Avena sativa L. v. Overberg ('Overberg' oats), as well as weedchem. During the third growing season of the vines (1994/95), the shoot mass of the BB treatments of grazing vetch and Medicago truncatula Gaertn. v. Paraggio ('Paraggio' medic) was significantly higher than that of the $\mathrm{AB}$ and $\mathrm{MC}$ treatments, with the exception of rye (AB) and grazing vetch (MC). The shoot mass of the $\mathrm{BB}$ and $\mathrm{AB}$ treatment of a species differed significantly, with the exception of rye and 'Overberg' oats, with the shoot mass of the $\mathrm{BB}$ treatment constantly being the higher of the two. Results indicated that, in young vineyards, the cover crops should be controlled chemically before bud break. This corresponded with the observations of Fourie et al. (2006). The use of grazing vetch as cover crop in combination with full surface, post-emergence chemical control before bud break was the most effective soil management practice to be applied in young vineyards to enhance the development of the permanent structure of trellised grapevines established on sandy soils in the warmer climatic regions.

The first harvest (1994/95) from the grapevines in the BB treatments was significantly higher than that of weedchem and the MC treatments (Table 1). The grape yield in the BB treatments of $M$. truncatula Gaertn. v. Parabinga ('Parabinga' medic), Ornithopus sativus L. v. Emena (pink Seradella), grazing vetch and 'Saia' oats was significantly more than that of the $A B$ treatments. A similar tendency was observed for rye (BB) and 'Paraggio' medic (BB). The grape yield of the latter two BB treatments was, however, not significantly higher than that of grazing vetch $(A B)$ and pink Seradella (AB). The grape yield of the $\mathrm{BB}$ and $\mathrm{AB}$ treatment of a species differed significantly, with the grape yield of the BB treatment being the higher of the two. This indicated that the cover crops which were controlled chemically before bud break had a significant positive impact on the grape yield of the young Sauvignon blanc/Ramsey vines established on a sandy soil. This supported the results of Fourie et al. (2006). The grape yield of the $\mathrm{AB}$ treatments in which a $\mathrm{N}$-fixing cover crop was established was, with the exception of 'Paraggio' medic, significantly higher than that of weedchem and the MC treatments. The grape yield of 
TABLE 1

Effect of three cover crop management practices applied selectively to three grain species and four N-fixing broadleaf species on the shoot mass (SM) and grape yield (GY) of young and full-bearing Sauvignon blanc/Ramsey vines, on a sandy soil near Lutzville.

\begin{tabular}{|c|c|c|c|c|c|c|c|c|c|}
\hline \multirow[b]{2}{*}{ Treatment } & \multirow{2}{*}{ 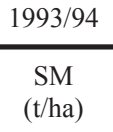 } & \multicolumn{2}{|c|}{$1994 / 95$} & \multicolumn{2}{|c|}{$1995 / 96$} & \multicolumn{2}{|c|}{$1997 / 98$} & \multicolumn{2}{|c|}{$2002 / 03$} \\
\hline & & $\begin{array}{c}\mathrm{SM} \\
(\mathrm{t} / \mathrm{ha})\end{array}$ & $\begin{array}{l}\text { GY } \\
(\mathrm{t} / \mathrm{ha})\end{array}$ & $\begin{array}{c}\text { SM } \\
(\mathrm{t} / \mathrm{ha})\end{array}$ & $\begin{array}{l}\text { GY } \\
(\mathrm{t} / \mathrm{ha})\end{array}$ & $\begin{array}{c}\text { SM } \\
(\mathrm{t} / \mathrm{ha})\end{array}$ & $\begin{array}{c}\mathrm{GY} \\
(\mathrm{t} / \mathrm{ha})\end{array}$ & $\begin{array}{c}\mathrm{SM} \\
(\mathrm{t} / \mathrm{ha})\end{array}$ & $\begin{array}{c}\mathrm{GY} \\
(\mathrm{t} / \mathrm{ha})\end{array}$ \\
\hline \multicolumn{10}{|l|}{ Grain species: } \\
\hline Secale cereale L. v. Henog (rye), BB ${ }^{1}$. & 0.62 & 2.11 & 6.54 & 3.29 & 12.51 & 3.02 & 11.32 & 2.89 & 13.09 \\
\hline Secale cereale L. v. Henog (rye) $\mathrm{AB}^{2}$. & 0.53 & 2.00 & 4.44 & $3.25^{4}$ & $12.02^{4}$ & $2.92^{4}$ & $10.67^{4}$ & 2.91 & 13.36 \\
\hline Avena sativa L. v. Overberg ('Overberg' oats), BB. & 0.57 & 2.31 & 5.02 & 3.51 & 11.26 & 3.00 & 11.74 & 2.92 & 14.32 \\
\hline Avena sativa L. v. Overberg ('Overberg' oats), AB. & 0.40 & 1.60 & 2.73 & $2.62^{4}$ & $10.31^{4}$ & $2.60^{4}$ & $9.09^{4}$ & 2.76 & 14.51 \\
\hline Avena strigosa L. v. Saia ('Saia’ oats), BB. & 0.84 & 2.53 & 7.76 & 4.01 & 12.31 & 3.25 & 11.13 & 2.78 & 13.45 \\
\hline Avena strigosa L. v. Saia ('Saia’ oats), AB. & 0.42 & 1.49 & 4.38 & $2.87^{4}$ & $10.44^{4}$ & $2.81^{4}$ & $9.33^{4}$ & 2.77 & 11.89 \\
\hline Avena strigosa L. v. Saia ('Saia' oats), $\mathrm{MC}^{3}$. & 0.40 & 1.62 & 1.47 & 3.03 & 10.56 & 2.38 & 9.83 & 2.39 & 12.00 \\
\hline \multicolumn{10}{|l|}{ N-fixing broadleaf species: } \\
\hline $\begin{array}{l}\text { Medicago truncatula Gaertn v. Paraggio } \\
\text { ('Paraggio' medic), BB. }\end{array}$ & 0.58 & 2.77 & 6.20 & 3.30 & 13.09 & 2.98 & 11.89 & 2.95 & 13.42 \\
\hline $\begin{array}{l}\text { Medicago truncatula Gaertn v. Paraggio } \\
\text { ('Paraggio' medic), AB. }\end{array}$ & 0.27 & 1.24 & 4.12 & $3.33^{4}$ & $12.83^{4}$ & $2.57^{4}$ & $9.03^{4}$ & 2.81 & 13.84 \\
\hline $\begin{array}{l}\text { Medicago truncatula Gaertn v. Parabinga } \\
\text { ('Parabinga' medic), BB. }\end{array}$ & 0.62 & 2.53 & 8.26 & 3.39 & 11.86 & 3.07 & 12.08 & 3.13 & 14.83 \\
\hline $\begin{array}{l}\text { Medicago truncatula Gaertn v. Parabinga } \\
\text { ('Parabinga' medic), AB. }\end{array}$ & 0.24 & 1.31 & 4.88 & $2.84^{4}$ & $11.18^{4}$ & $2.52^{4}$ & $9.53^{4}$ & 2.76 & 13.40 \\
\hline Ornithopus sativus L. v. Emena (pink Seradella), BB & 0.51 & 2.54 & 7.30 & 4.71 & 14.73 & 4.07 & 12.09 & 3.16 & 14.25 \\
\hline Ornithopus sativus L. v. Emena (pink Seradella), AB & 0.40 & 1.56 & 5.55 & $3.82^{4}$ & $11.66^{4}$ & $3.81^{4}$ & $11.21^{4}$ & 3.19 & 14.01 \\
\hline Vicia dasycarpa Ten. (grazing vetch),BB. & 0.56 & 2.91 & 8.19 & 4.65 & 15.37 & 4.08 & 11.35 & 2.72 & 14.49 \\
\hline Vicia dasycarpa Ten. (grazing vetch), AB. & 0.44 & 1.78 & 5.32 & $3.60^{4}$ & $12.96^{4}$ & $4.04^{4}$ & $11.58^{4}$ & 3.11 & 13.65 \\
\hline Vicia dasycarpa Ten. (grazing vetch), MC. & 0.33 & 2.16 & 3.29 & 4.57 & 10.82 & 3.13 & 11.49 & 2.39 & 12.05 \\
\hline Weeds, MC (control). & 0.51 & 1.69 & 2.54 & 2.58 & 10.35 & 2.79 & 8.69 & 2.18 & 11.92 \\
\hline Weeds, BB (weedchem). & 0.60 & 2.02 & 3.00 & 3.39 & 11.33 & 2.91 & 9.07 & 2.40 & 11.97 \\
\hline $\operatorname{LSD}(\mathrm{p} \leq 0.05)$ & 0.29 & 0.95 & 1.54 & 1.44 & 2.20 & 1.10 & 2.02 & 0.77 & 1.62 \\
\hline
\end{tabular}

${ }^{1} \mathrm{BB}=$ full surface chemical control before bud break. ${ }^{2} \mathrm{AB}=$ full surface chemical control at the end of November (1993 to 1998$)$ and mid-October (1999 to 2002 ).

${ }^{3} \mathrm{MC}=$ chemical control in vine row, mechanical control in working row. ${ }^{4}$ Cover crop left to re-establish.

'Paraggio' medic $(\mathrm{AB})$, rye $(\mathrm{AB})$ and 'Saia' oats $(\mathrm{AB})$ was significantly higher than that of the control and 'Saia' oats (MC), while that of 'Overberg' oats (AB) did not differ significantly from weedchem, the control and the two MC treatments in which a cover crop was established. These results differed from that reported by Fourie et al. (2006) for irrigated young Chardonnay/99 Richter vines and Van Huyssteen \& Weber (1980) for non-irrigated full-bearing Chenin blanc vines, both of which were established on medium textured soils near Stellenbosch. The K and N applied two weeks after bud break in the present study could have reduced the impact that the cover crops, left to grow until berry set, might have had on the young Sauvignon blanc/Ramsey vines. Competition from summer growing weeds was low (Fourie et al., 2005), which seemed to benefit the AB treatments as well.

The cover crops performed poorly during the 1995/96 season (Fourie et al., 2005), the first season in which the grapevines were in full production (Table 1). This could have contributed to the differences in shoot mass and harvest mass between treatments not manifesting as clearly during the 1995/96 season as in the case of the 1994/95 season. Despite this, the shoot mass of the grapevines in pink Seradella (BB), grazing vetch (BB) and graz- ing vetch (MC) exceeded $4.5 \mathrm{t} / \mathrm{ha}$. These results, as well as visual evaluation of the grapevine canopies during the growing season, indicated that the grapevines in these three treatments were developing dense canopies. Champagnol (1978), Hunter \& Visser (1990) and Smart et al. (1990) indicated that increased vegetative growth may reduce yields due to excessive shading of fruiting zones, which may result in decreased fruitfulness of the buds in the following season. To prevent this from happening, the amount of $\mathrm{N}$ applied after bud break in these three treatments was reduced by $50 \%$ (21 kg of N/ha) from the 1996/97 season onwards. The highest grape yield was observed for grazing vetch (BB) during the 1995/96 season. It was significantly higher than that of the other treatments, with the exception of pink Seradella (BB). Pink Seradella yielded significantly more grapes than the other treatments, with the exception of the two 'Paraggio' medic treatments and the $\mathrm{BB}$ and $\mathrm{AB}$ treatments of grazing vetch. These results indicated that grazing vetch or pink Seradella controlled chemically before bud break should enhance the performance of grapevines on a sandy soil in the Olifants River Valley (Table 1), even when producing less than 1.1 tons of dry matter per hectare (Fourie et al., 2005). The grape yield of 'Paraggio' medic (BB) was signifi- 
cantly higher than that of the MC treatments and exceeded that of weedchem and the $\mathrm{AB}$ treatments as well, although these differences were not always significant (Table 1). This indicated that 'Paraggio' medic, producing as little as $0.58 \mathrm{t} / \mathrm{ha}$ of dry matter (Fourie et al., 2005), could also enhance grapevine performance on a sandy soil.

Although the $\mathrm{N}$ applied after bud break in pink Seradella (BB) and grazing vetch (BB) was reduced by $50 \%$ from the 1996/97 season onwards, the shoot growth during the 1997/98 season (fifth season of the experiment) was still the highest and significantly higher than that of the control, weedchem, 'Saia' oats (MC), as well as the AB treatments of the grain species and two Medicago species (Table 1). The grape yield/shoot mass ratio in the two BB treatments was less than 3 . This was much lower than the ratio of 3.6 considered by Conradie (2001a) to indicate excessive growth for Bukettraube/Ramsey grapevines under supplementary irrigation on a duplex Kroonstad soil form (Soil Classification Working Group, 1991). From the 1998/99 season onwards, therefore, no $\mathrm{N}$ was applied after bud break in these two BB treatments. A similar result was obtained with grazing vetch $(\mathrm{AB})$, indicating that the amount of $\mathrm{N}$ applied after bud break should be reduced for this treatment as well (Table 1). Although the shoot growth of the grapevines in pink Seradella (AB) was less than that of the above-mentioned BB treatments, the grape yield/shoot mass ratio was also less than three, indicating excessive shoot growth. The amount of $\mathrm{N}$ applied in grazing vetch $(\mathrm{AB})$ and pink Seradella (AB) was, therefore, reduced by $50 \%(21 \mathrm{~kg}$ of $\mathrm{N} / \mathrm{ha}$ ) from the 1998/99 season onwards. The grape yield of the BB treatments, grazing vetch $(\mathrm{AB})$ and pink Seradella $(\mathrm{AB})$ was significantly higher than that of weedchem and the control during the 1997/98 season, indicating that these treatments should preferably be applied over the medium term in full bearing vineyards established on sandy soils in the Olifants River Valley. Although the grape yield of the $\mathrm{AB}$ treatments of the two Medicago species and 'Overberg' oats was significantly less than that of the BB treatments of these three species, indicating that these treatments impacted negatively on grapevine performance, it was similar to that of weedchem, the control and Saia (MC).

The cover crops in the AB treatments were controlled during mid-October from the 1999/2000 to the 2002/03 seasons (second phase of the trial). Results of the 2002/03 season (tenth season of the trial), which were representative of grapevine performance during this period, are shown in Table 1. The shoot growth in the two pink Seradella treatments, grazing vetch $(\mathrm{AB})$ and 'Parabinga' medic (BB) was significantly higher than that of weedchem, 'Saia' oats (MC) and the control. The shoot growth in these cover crop treatments were not excessive, however, as the yield/shoot mass ratios were between 4.36 and 4.73 , which is similar to the ratios reported by Conradie (2001a) and Zeeman \& Archer (1981) for grapevines considered to have a balanced growth pattern. The grape yield in the 'Overberg' oats and pink Seradella treatments, the BB treatments of 'Parabinga' medic and grazing vetch, as well as the AB treatments of 'Paraggio' medic and grazing vetch was significantly higher than that of weedchem, 'Saia' oats (MC) and the control (Table 1). This indicated that these treatments should preferably be applied in vineyards established on the sandy soils of the Olifants River Valley, as they enhanced grapevine performance over the medium to long term. In the case of pink Seradella and grazing vetch the enhanced performance was achieved, despite a reduction ( $\mathrm{AB}$ treatments) or omission (BB treatments) of the $\mathrm{N}$ fertilizer applied after bud break. Although the differences were not significant, the grape yield in the other minimum cultivated cover crop treatments, with the exception of 'Saia' oats (AB), exceeded that of weedchem by between 1.12 and $1.48 \mathrm{t} /$ ha. In contrast to the $1997 / 98$ season, the grape yield in the AB treatments of 'Overberg' oats and 'Paraggio' medic did not differ significantly from that of the BB treatments of the same species during the 2002/03 season (Table 1). This was attributed to the chemical control being applied six weeks earlier (mid-October instead of the end of November). Similar results were achieved with the other cover crop species during the 2002/03 season. This supported the results of Pool et al. (1990), who found that chemical weed control before bud break or at bloom, respectively, did not affect the vegetative growth or yield of 'Concord' grapevines.

\section{Berry mass and volume}

No significant differences in either berry mass or berry volume were observed (data not shown), which is similar to the results reported by Fourie et al. (2006).

\section{Leaf petiole analysis}

The trends between treatments differed significantly between years during both phases of the trial (1993/94 to 1998/99 and $1999 / 2000$ to $2002 / 03$ ). The $\mathrm{NO}_{3}-\mathrm{N}$ concentration of the petioles for years selected to illustrate the impact that the cover crops and cover crop management practices had on grapevine nutrient status early in the grapevine growing season over time, are presented in Table 2. The $\mathrm{NO}_{3}-\mathrm{N}$ concentration in the petioles of the young grapevines (1994/95 season) indicated that, according to the norms of Conradie (1994), only the vines in the BB treatments of pink Seradella and grazing vetch were sufficiently supplied with $\mathrm{N}$ early in the grapevine growing season (Table 2). The $\mathrm{NO}_{3}-\mathrm{N}$ concentration in the petioles of all the cover crop treatments was, with the exception of the AB treatments of rye, 'Parabinga' medic and grazing vetch, significantly more than that of weedchem and the control (Table 2). This indicated the importance of applying cover crop management, preferably with an N-fixing cover crop such as pink Seradella or grazing vetch, in young vineyards established on the sandy soils of the Olifants River Valley. The $\mathrm{NO}_{3}-\mathrm{N}$ concentration in the petioles of the $\mathrm{BB}$ and $\mathrm{AB}$ treatment of a species differed significantly, with that of the BB treatment being the higher of the two, making the latter the preferred cover crop management practice to be applied in young grapevines.

Although the cover crops performed poorly during the 1995/96 season (Fourie et al., 2006), the first season in which the grapevines were in full production (Table 1 ), the $\mathrm{NO}_{3}-\mathrm{N}$ concentrations in the BB treatments and grazing vetch (MC) indicated that these grapevines were adequately supplied with $\mathrm{N}$ (Table 2), according to the norms of Conradie (1994). The growing cover crops in the $\mathrm{AB}$ treatments competed with the grapevines for $\mathrm{N}$ early in the growing season, causing the vines to be slightly, and in the case of 'Parabinga' medic (AB) severely, under-supplied with $\mathrm{N}$ (Table 2). 'Saia' oats (MC), weedchem and the control were also slightly under-supplied with $\mathrm{N}$ during the early grapevine growing season. This could be attributed to the inorganic $\mathrm{N}$ applied after bud break being fixed by the degradation process initiated by the incorporation of the 'Saia' oats fibre or weeds into the top soil, as well as leaching of $\mathrm{N}$ from the grapevine root zone pro- 
TABLE 2

Effect of three cover crop management practices applied selectively to three grain species and four N-fixing broadleaf species on the $\mathrm{NO}_{3}-\mathrm{N}$ concentration in leaf petioles during full bloom of young and full bearing Sauvignon blanc/Ramsey vines on a sandy soil near Lutzville.

\begin{tabular}{|c|c|c|c|c|c|}
\hline \multirow{2}{*}{ Treatment } & \multicolumn{5}{|c|}{$\mathrm{NO}_{3}-\mathrm{N}(\mathrm{mg} / \mathrm{kg})$} \\
\hline & $1994 / 95$ & 1995/96 & $1997 / 98$ & 1998/99 & 2002/03 \\
\hline \multicolumn{6}{|l|}{ Grain species: } \\
\hline Secale cereale L. v. Henog (rye), BB ${ }^{1}$. & 550 & 735 & 771 & 753 & 983 \\
\hline Secale cereale L. v. Henog (rye) $\mathrm{AB}^{2}$. & 430 & $305^{4}$ & $537^{4}$ & 536 & 858 \\
\hline Avena sativa L. v. Overberg ('Overberg’ oats), BB. & 640 & 731 & 890 & 776 & 965 \\
\hline Avena sativa L. v. Overberg ('Overberg' oats), AB. & 500 & $469^{4}$ & $534^{4}$ & 555 & 913 \\
\hline Avena strigosa L. v. Saia (‘Saia’ oats), BB. & 597 & 742 & 917 & 837 & 994 \\
\hline Avena strigosa L. v. Saia ('Saia’ oats), AB. & 510 & $552^{4}$ & $442^{4}$ & 538 & 900 \\
\hline Avena strigosa L. v. Saia ('Saia' oats), $\mathrm{MC}^{3}$. & 495 & 597 & 533 & 471 & 661 \\
\hline \multicolumn{6}{|l|}{ N-fixing broadleaf species: } \\
\hline Medicago truncatula Gaertn v. Paraggio ('Paraggio' medic), BB. & 550 & 727 & 1436 & 911 & 1300 \\
\hline Medicago truncatula Gaertn v. Paraggio ('Paraggio’ medic), AB. & 496 & $428^{4}$ & $1184^{4}$ & 760 & 892 \\
\hline Medicago truncatula Gaertn v. Parabinga ('Parabinga' medic), BB. & 670 & 957 & 1504 & 847 & 1464 \\
\hline Medicago truncatula Gaertn v. Parabinga ('Parabinga' medic), AB. & 415 & $230^{4}$ & $887^{4}$ & 807 & 992 \\
\hline Ornithopus sativus L. v. Emena (pink Seradella), BB & 816 & 1080 & 2020 & 996 & 984 \\
\hline Ornithopus sativus L. v. Emena (pink Seradella), AB & 560 & $584^{4}$ & $2776^{4}$ & 939 & 1053 \\
\hline Vicia dasycarpa Ten. (grazing vetch),BB. & 806 & 1205 & 1042 & 881 & 928 \\
\hline Vicia dasycarpa Ten. (grazing vetch), AB. & 470 & $368^{4}$ & $2088^{4}$ & 976 & 1646 \\
\hline Vicia dasycarpa Ten. (grazing vetch), MC. & 526 & 1009 & 1193 & 890 & 950 \\
\hline Weeds, MC (control). & 426 & 516 & 715 & 626 & 617 \\
\hline Weeds, BB (weedchem). & 422 & 504 & 704 & 628 & 651 \\
\hline $\operatorname{LSD}(\mathrm{p} \leq 0.05)$ & 68 & 130 & 176 & 85 & 171 \\
\hline
\end{tabular}

${ }^{1} \mathrm{BB}=$ full surface chemical control before bud break. ${ }^{2} \mathrm{AB}=$ full surface chemical control at the end of November (1993 to 1998$)$ and mid-October (1999 to 2002$)$.

${ }^{3} \mathrm{MC}=$ chemical control in vine row, mechanical control in working row. ${ }^{4}$ Cover crop left to re-establish.

moted by the cultivation of the soil. The $\mathrm{NO}_{3}-\mathrm{N}$ concentration in the BB treatments of 'Parabinga' medic, pink Seradella and grazing vetch, as well as grazing vetch (MC), was significantly higher than that of the BB treatments of the grain species. These N-fixing cover crops, therefore, supplied significant amounts of $\mathrm{N}$ to the grapevines during the early part of the growing season if controlled chemically or mechanically before bud break. According to the norms of Conradie (1994), this resulted in an over-supply of $\mathrm{N}$ in the case of pink Seradella and grazing vetch (Table 2), which led to excessive shoot growth (Table 1).

All the treatments sown with $\mathrm{N}$-fixing cover crops, except 'Parabinga' medic (AB), were over-supplied with $\mathrm{N}$ during the early part of the 1997/98 grapevine growing season (Table 2), showing that 'Paraggio' medic, pink Seradella and grazing vetch impacted significantly on the $\mathrm{N}$ status of grapevines established on sandy soils in this region, irrespective of the management practice applied. Reducing the amount of $\mathrm{N}$ applied after bud break in the BB treatments of pink Seradella and grazing vetch, as well as grazing vetch (MC) by 50\% for two seasons (1996/97 and 1997/98), therefore, did not suffice. In the case of the minimum cultivation treatments of grazing vetch and the pink Seradella, this over-supply of $\mathrm{N}$ led to excessive vegetative growth (Table 1). Reducing the amount of $\mathrm{N}$ applied after bud break in the $\mathrm{AB}$ treatments of grazing vetch and the pink Seradella by $50 \%$ and omitting the application of $\mathrm{N}$ after bud break in the BB treatments of these two species from the 1998/99 season onwards, normalized the N status of the grapevines during the early part of the growing season (Table 2). The amount of $\mathrm{N}$ applied after bud break in the two 'Paraggio' medic treatments and 'Parabinga' medic (BB), was not reduced, as the shoot growth in these treatments was not excessive during the 1997/98 season (Table 1). The normalization of the $\mathrm{NO}_{3}-\mathrm{N}$ levels in these treatments in the following season was attributed to the poor performance of the cover crops, rendering them unable to supply the amount of $\mathrm{N}$ to the grapevines that caused the luxurious supply during the previous season. The grain species that were controlled chemically during berry set competed with the grapevines for nutrients throughout the first phase of the trial (1993/94 to 1998/99). This resulted in the grapevines in these treatments being slightly under-supplied with $\mathrm{N}$ early in the growing season (Table 2). Similar results were achieved with 'Saia' oats (MC), weedchem and the control. The $\mathrm{NO}_{3}-\mathrm{N}$ concentration in the petioles of the grapevines in rye (AB), 'Saia' oats (AB) and 'Saia' oats (MC) was significantly less than that of weedchem and the control during the 1998/99 season (sixth season of the trial), indicating that the first-mentioned treatments had a significantly negative impact on the early season $\mathrm{N}$ status of the grapevines over the medium term. These treatments should not, therefore, be applied on the sandy soils of the Olifants River Valley. 
During the second phase of the trial (1999/2000 to 2002/03) chemical control was applied mid-October in the $\mathrm{AB}$ treatments. The cover crops performed well during the 2001/02 and 2002/03 seasons (Fourie et al., 2005), which resulted in the $\mathrm{NO}_{3}-\mathrm{N}$ concentrations of the cover crop treatments, with the exception of 'Saia' oats (MC), being significantly higher than that of weedchem and the control (Table 2). The $\mathrm{NO}_{3}-\mathrm{N}$ concentrations in the BB treatments of the Medicago species, as well as the AB treatments of pink Seradella and grazing vetch, however, indicated that the grapevines in these four treatments were over-supplied with N. The results suggest that the inorganic $\mathrm{N}$ applied in these four treatments should be reduced for the first-mentioned two treatments and omitted for the last-mentioned two species. The results indicated that pink Seradella and grazing vetch should preferably be controlled chemically during or before mid-October to optimize the supply of $\mathrm{N}$ to the grapevines during the early part of the growing season without the use of inorganic $\mathrm{N}$ during the growing season.

\section{Juice analysis}

The trends between treatments differed significantly between years as far as the sugar content, total acidity and $\mathrm{pH}$ were concerned. Trends between the $\mathrm{BB}$ and $\mathrm{AB}$ treatments within species, however, remained fairly consistent. The trend between weedchem and the control on the one hand and the cover crop management practices on the other also remained fairly consistent. To illustrate the trends that did occur, the results as measured during the fifth
(1997/98) season of the experiment, a season during which the cover crops performed well, are presented in Table 3. The sugar content of the juice in the three MC treatments, weedchem, and 'Parabinga' medic (AB) was significantly higher than that of the two pink Seradella treatments, 'Saia' oats (BB), 'Parabinga' medic $(\mathrm{BB})$ and grazing vetch $(\mathrm{BB})$. The sugar content of the juice in the $\mathrm{AB}$ treatments also tended to be higher than that of the BB treatments, with the exception of pink Seradella. In the case of grazing vetch, this difference was significant. The total acidity of the juice in 'Parabinga' medic (BB) and pink Seradella (BB) was significantly higher than that of grazing vetch (MC), the $A B$ treatments of the grain species and the $\mathrm{AB}$ treatments of the Medicago species. The total acidity of the juice in 'Saia' oats (BB), grazing vetch (BB) and pink Seradella $(A B)$ was also higher than that of grazing vetch (MC), as well as the AB treatments of 'Overberg' oats, 'Saia' oats and 'Parabinga' medic. The total acidity of the juice in the BB treatments also tended to be higher than that of the AB treatments, with the exception of pink Seradella and grazing vetch, thus agreeing with the lower sugar contents. These trends were ascribed to crop sizes, as well as differences in vegetative growth and supported the results of Conradie (2001b) and Fourie et al. (2006).

The trends in the $\mathrm{N}$ concentration in the juice between treatments differed significantly between years during both phases of the trial (1993/94 to $1998 / 99$ and $1999 / 2000$ to $2002 / 03)$. The N concentration of the juice in the years selected to illustrate the

\section{TABLE 3}

Effect of three cover crop management practices applied selectively to three grain species and four N-fixing broadleaf species on sugar, titratable acidity and $\mathrm{pH}$ of full bearing Sauvignon blanc/Ramsey vines on a sandy soil near Lutzville, during the fifth (1997/98) season.

\begin{tabular}{|c|c|c|c|}
\hline Treatment & $\begin{array}{c}\text { Sugar } \\
\left({ }^{\circ} \mathrm{B}\right)\end{array}$ & $\begin{array}{c}\text { Total acids } \\
\text { (g/L) }\end{array}$ & pH \\
\hline \multicolumn{4}{|l|}{ Grain species: } \\
\hline Secale cereale L. v. Henog (rye), $\mathrm{BB}^{1}$. & 22.5 & 8.17 & 3.13 \\
\hline Secale cereale L. v. Henog (rye) $\mathrm{AB}^{2}$. & $22.6^{4}$ & $7.70^{4}$ & $3.16^{4}$ \\
\hline Avena sativa L. v. Overberg ('Overberg' oats), BB. & 22.3 & 7.87 & 3.14 \\
\hline Avena sativa L. v. Overberg ('Overberg' oats), AB. & $22.6^{4}$ & $7.53^{4}$ & $3.15^{4}$ \\
\hline Avena strigosa L. v. Saia ('Saia’ oats), BB. & 22.0 & 8.53 & 3.04 \\
\hline Avena strigosa L. v. Saia ('Saia’ oats), AB. & $22.6^{4}$ & $7.40^{4}$ & $3.13^{4}$ \\
\hline Avena strigosa L. v. Saia ('Saia' oats), MC³. & 22.8 & 8.03 & 3.05 \\
\hline \multicolumn{4}{|l|}{ N-fixing broadleaf species: } \\
\hline Medicago truncatula Gaertn v. Paraggio ('Paraggio' medic), BB. & 22.5 & 7.87 & 3.15 \\
\hline Medicago truncatula Gaertn v. Paraggio ('Paraggio' medic), AB. & $22.7^{4}$ & $7.70^{4}$ & $3.17^{4}$ \\
\hline Medicago truncatula Gaertn v. Parabinga ('Parabinga' medic), BB. & 22.0 & 8.70 & 3.11 \\
\hline Medicago truncatula Gaertn v. Parabinga ('Parabinga' medic), AB. & $22.9^{4}$ & $7.37^{4}$ & $3.09^{4}$ \\
\hline Ornithopus sativus L. v. Emena (pink Seradella), BB & 21.6 & 8.77 & 3.14 \\
\hline Ornithopus sativus L. v. Emena (pink Seradella), AB & $21.8^{4}$ & $8.53^{4}$ & $3.15^{4}$ \\
\hline Vicia dasycarpa Ten. (grazing vetch),BB. & 21.5 & 8.57 & 3.17 \\
\hline Vicia dasycarpa Ten. (grazing vetch), AB. & $22.3^{4}$ & $8.17^{4}$ & $3.15^{4}$ \\
\hline Vicia dasycarpa Ten. (grazing vetch), MC. & 23.0 & 7.37 & 3.12 \\
\hline Weeds, MC (control). & 22.8 & 7.83 & 3.10 \\
\hline Weeds, BB (weedchem). & 22.8 & 8.0 & 3.09 \\
\hline $\operatorname{LSD}(p \leq 0.05)$ & 0.7 & 0.97 & $\mathrm{NS}^{5}$ \\
\hline
\end{tabular}

${ }^{1} \mathrm{BB}=$ full surface chemical control before bud break. ${ }^{2} \mathrm{AB}=$ full surface chemical control at the end of November (1993 to 1998$)$ and mid-October (1999 to 2002). ${ }^{3} \mathrm{MC}=$ chemical control in vine row, mechanical control in working row. ${ }^{4}$ Cover crop left to re-establish. ${ }^{5}$ Values do not differ significantly at the $5 \%$ probability level. 
impact that the cover crops and cover crop management practices had on the $\mathrm{N}$ concentration in the juice over time are presented in Table 4. The $\mathrm{N}$ concentration in the juice of the cover crop treatments during the 1995/96 season (the first season in which the grapevines were in full production) was, with the exception of 'Saia' oats (MC) and 'Parabinga' medic ( $\mathrm{AB})$, significantly higher than that of weedchem and the control. The $\mathrm{N}$ concentration in the juice of pink Seradella $(\mathrm{AB})$ was significantly higher than that of all the other treatments except 'Parabinga' medic (BB). This indicated that pink Seradella controlled chemically during berry set (end of November) supplied a significant amount of $\mathrm{N}$ to the grapevines from flowering to harvest. Although the grapevines in the BB treatments of pink Seradella and grazing vetch experienced an over-supply of $\mathrm{N}$ during the early part of the 1995/96 growing season of the grapevines (Table 2), excess $\mathrm{N}$ was not found in the juice (Table 4). The under-supply of $\mathrm{N}$ that the grapevines in 'Parabinga' medic (AB) experienced early in the 1995/96 growing season was also not apparent during harvest. With the exception of pink Seradella and grazing vetch, it tended to be beneficial for the $\mathrm{N}$ concentration of the juice of four year old grapevines if a cover crop species was controlled chemically before bud break on the sandy soils of the Olifants River Valley. The abnormally low values (W.J. Conradie - personal communication, 2006) observed for the treatments in which no cover crops were sown, namely weedchem and the control (Table 4), indicated that cover crop management played an important role to help ensure that the grapevines were sufficiently supplied with $\mathrm{N}$ throughout the grapevine growing season on sandy soils.

The $\mathrm{N}$ concentration of the juice in 'Parabinga' medic (BB), as well as the treatments in which grazing vetch and pink Seradella was established, was significantly higher than that of the other treatments during the 1997/98 season. These results were achieved with grazing vetch (BB) and pink Seradella (BB), despite a $50 \%$ reduction in the amount of inorganic $\mathrm{N}$ applied after bud break. This indicated that grazing vetch and pink Seradella supplied a significant amount of $\mathrm{N}$ to the grapevines from flowering to harvest, irrespective of the management practice applied, while 'Parabinga' medic had to be controlled chemically before bud break to achieve similar results. The abnormally high concentration of $\mathrm{N}$ in the juice of the grazing vetch $(\mathrm{AB})$ treatment indicated that the grapevines were not only over-supplied with $\mathrm{N}$ during the early part of the growing season (Table 2), but also from flowering to harvest (Table 4). The $\mathrm{N}$ concentration of the juice in the BB and AB treatments of grazing vetch and pink Seradella was significantly higher than that of the $\mathrm{MC}$ treatments, the two rye treatments, weedchem, as well as the AB treatments of the other cover crop species, as measured during the 1998/99 season. This was realized despite the fact that the BB treatments of grazing vetch and pink Seradella received no $\mathrm{N}$ after bud break and the amount of $\mathrm{N}$ applied after bud break in the AB treatments of these two species were reduced by $50 \%$. This confirmed that pink Seradella and grazing vetch contributed significantly to the

\section{TABLE 4}

Effect of three cover crop management practices applied selectively to three grain species and four N-fixing broadleaf species on the $\mathrm{N}$ concentration in the juice of Sauvignon blanc/Ramsey vines on a sandy soil near Lutzville.

\begin{tabular}{|c|c|c|c|c|}
\hline \multirow{2}{*}{ Treatment } & \multicolumn{4}{|c|}{ N (mg/kg) } \\
\hline & 1995/96 & $1997 / 98$ & $1998 / 99$ & 2002/03 \\
\hline \multicolumn{5}{|l|}{ Grain species: } \\
\hline Secale cereale L. v. Henog (rye), $\mathrm{BB}^{1}$. & 569 & 631 & 548 & 642 \\
\hline Secale cereale L. v. Henog (rye) $\mathrm{AB}^{2}$. & $557^{4}$ & $626^{4}$ & 543 & 649 \\
\hline Avena sativa L. v. Overberg ('Overberg’ oats), BB. & 625 & 649 & 573 & 652 \\
\hline Avena sativa L. v. Overberg ('Overberg' oats), AB. & $538^{4}$ & $612^{4}$ & 401 & 586 \\
\hline Avena strigosa L. v. Saia ('Saia’ oats), BB. & 595 & 638 & 581 & 584 \\
\hline Avena strigosa L. v. Saia ('Saia' oats), AB. & $557^{4}$ & $520^{4}$ & 386 & 653 \\
\hline Avena strigosa L. v. Saia ('Saia' oats), MC'. & 514 & 509 & 380 & 509 \\
\hline \multicolumn{5}{|l|}{ N-fixing broadleaf species: } \\
\hline Medicago truncatula Gaertn v. Paraggio ('Paraggio' medic), BB. & 652 & 648 & 676 & 765 \\
\hline Medicago truncatula Gaertn v. Paraggio ('Paraggio' medic), AB. & $625^{4}$ & $653^{4}$ & 514 & 736 \\
\hline Medicago truncatula Gaertn v. Parabinga ('Parabinga' medic), BB. & 765 & 846 & 611 & 780 \\
\hline Medicago truncatula Gaertn v. Parabinga ('Parabinga' medic), AB. & $522^{4}$ & $624^{4}$ & 532 & 690 \\
\hline Ornithopus sativus L. v. Emena (pink Seradella), BB & 659 & 757 & 615 & 640 \\
\hline Ornithopus sativus L. v. Emena (pink Seradella), AB & $903^{4}$ & $866^{4}$ & 664 & 748 \\
\hline Vicia dasycarpa Ten. (grazing vetch),BB. & 676 & $824^{4}$ & 705 & 829 \\
\hline Vicia dasycarpa Ten. (grazing vetch), AB. & $732^{4}$ & 1165 & 730 & 1049 \\
\hline Vicia dasycarpa Ten. (grazing vetch), MC. & 668 & 798 & 544 & 583 \\
\hline Weeds, MC (control). & 391 & 604 & 513 & 597 \\
\hline Weeds, BB (weedchem). & 360 & 565 & 554 & 601 \\
\hline $\operatorname{LSD}(p \leq 0.05)$ & 149 & 81 & 68 & 100 \\
\hline
\end{tabular}

${ }^{1} \mathrm{BB}=$ full surface chemical control before bud break. ${ }^{2} \mathrm{AB}=$ full surface chemical control at the end of November (1993 to 1998$)$ and mid-October (1999 to 2002$)$.

${ }^{3} \mathrm{MC}=$ chemical control in vine row, mechanical control in working row. ${ }^{4}$ Cover crop left to re-establish. 
$\mathrm{N}$ status of the grapevines in the medium term (sixth season of the experiment), even when allowed to grow until the grapevines reached the berry set stage.

The $\mathrm{N}$ concentration in the juice of the grazing vetch $(\mathrm{AB})$ treatment during the second phase of the trial was significantly higher than that of the other treatments and indicated that the inorganic $\mathrm{N}$ applied in this treatment should be withdrawn to prevent an over-supply of $\mathrm{N}$ to the grapevines in the period from flowering to harvest (Table 4). The $\mathrm{N}$ concentration in the juice of the $\mathrm{BB}$ treatments of grazing vetch and the two Medicago species was significantly higher than that of weedchem, the control and the treatments in which the grain species were sown. This indicated that grazing vetch and the two Medicago species combined with chemical control before bud break made a significant contribution towards the $\mathrm{N}$ status of the grapevines from flowering to harvest. As a high residual $\mathrm{N}$ content in the must may encourage microbial instability (Jiranek et al., 1995) and ethyl carbamate accumulation in wine (Ough, 1991; Henschke \& Jiranek, 1993), the N status of the grapevines will need to be monitored annually if these treatments are applied over the long term in full bearing vineyards on sandy soils in the Olifants River Valley.

The $\mathrm{P}, \mathrm{K}, \mathrm{Ca}$ and $\mathrm{Mg}$ concentrations in the juice fluctuated from season to season, but trends remained fairly consistent. The mean values for the period 1995/96 to 1999/2000 are shown in Table 5. The concentration of $\mathrm{K}$ in the juice of the $\mathrm{AB}$ treatments of the two Medicago species was significantly lower than that of weed- chem, indicating that these two species competed with the grapevines for $\mathrm{K}$ during the growing season if controlled chemically after bud break. The concentration of $\mathrm{P}$ in the juice of grazing vetch $(\mathrm{BB})$ was significantly higher than that of the other treatments. The concentration of $\mathrm{Ca}$ in the juice of the cover crop treatments was, with the exception of the pink Seradella treatments, significantly higher than that of weedchem and the control. The concentration of $\mathrm{Mg}$ in the juice of the $\mathrm{BB}$ and $\mathrm{AB}$ treatments of grazing vetch was significantly higher than that of weedchem, the control and the AB treatments of the two Medicago species and pink Seradella. This could be attributed to these minerals being consumed by the relevant cover crops during its growing season and released from its fibre during the growing season of the grapevines.

\section{Wine quality}

Wine quality was not influenced by the different soil cultivation treatments (data not shown). This was similar to the results reported by Fourie et al. (2006) for Chardonnay/99 Richter vines established on a medium textured soil near Stellenbosch.

\section{CONCLUSIONS}

The effect of the different soil management practices started manifesting as early as the first season in which the treatments were applied. Annual sowing of a cover crop, preferably grazing vetch, in combination with full surface, post-emergence chemical control from just before bud break (BB), proved to be the most

\section{TABLE 5}

Effect of three cover crop management practices applied selectively to three grain species and four N-fixing broadleaf species on the $\mathrm{P}, \mathrm{K}, \mathrm{Ca}$ and $\mathrm{Mg}$ concentrations in the juice of Sauvignon blanc/Ramsey vines on a sandy soil near Lutzville.

\begin{tabular}{|c|c|c|c|c|}
\hline Treatment & $\mathbf{P}(\mathrm{mg} / \mathrm{L})$ & $\mathrm{K}(\mathrm{mg} / \mathrm{L})$ & $\mathrm{Ca}(\mathrm{mg} / \mathrm{L})$ & $\operatorname{Mg}(\mathrm{mg} / \mathrm{L})$ \\
\hline \multicolumn{5}{|l|}{ Grain species: } \\
\hline Secale cereale L. v. Henog (rye), $\mathrm{BB}^{1}$. & 94 & 1324 & 53 & 92 \\
\hline Secale cereale L. v. Henog (rye) $\mathrm{AB}^{2}$. & 91 & 1308 & 52 & 87 \\
\hline Avena sativa L. v. Overberg ('Overberg' oats), BB. & 97 & 1281 & 62 & 90 \\
\hline Avena sativa L. v. Overberg ('Overberg' oats), AB. & 100 & 1297 & 62 & 89 \\
\hline Avena strigosa L. v. Saia ('Saia’ oats), BB. & 98 & 1166 & 57 & 89 \\
\hline Avena strigosa L. v. Saia ('Saia' oats), AB. & 104 & 1365 & 60 & 91 \\
\hline Avena strigosa L. v. Saia ('Saia' oats), MC'. & 96 & 1316 & 66 & 90 \\
\hline \multicolumn{5}{|l|}{ N-fixing broadleaf species: } \\
\hline Medicago truncatula Gaertn v. Paraggio ('Paraggio' medic), BB. & 85 & 1155 & 55 & 87 \\
\hline Medicago truncatula Gaertn v. Paraggio ('Paraggio' medic), AB. & 88 & 1024 & 52 & 80 \\
\hline Medicago truncatula Gaertn v. Parabinga ('Parabinga' medic), BB. & 98 & 1198 & 61 & 88 \\
\hline Medicago truncatula Gaertn v. Parabinga ('Parabinga' medic), AB. & 101 & 1058 & 59 & 85 \\
\hline Ornithopus sativus L. v. Emena (pink Seradella), BB & 95 & 1327 & 46 & 86 \\
\hline Ornithopus sativus L. v. Emena (pink Seradella), AB & 92 & 1258 & 36 & 78 \\
\hline Vicia dasycarpa Ten. (grazing vetch),BB. & 116 & 1395 & 67 & 95 \\
\hline Vicia dasycarpa Ten. (grazing vetch), AB. & 100 & 1256 & 58 & 96 \\
\hline Vicia dasycarpa Ten. (grazing vetch), MC. & 92 & 1214 & 62 & 92 \\
\hline Weeds, MC (control). & 93 & 1240 & 41 & 84 \\
\hline Weeds, BB (weedchem). & 97 & 1303 & 40 & 85 \\
\hline $\operatorname{LSD}(\mathrm{p} \leq 0.05)$ & 13 & 157 & 10 & 9 \\
\hline
\end{tabular}

${ }^{1} \mathrm{BB}=$ full surface chemical control before bud break. ${ }^{2} \mathrm{AB}=$ full surface chemical control at the end of November (1993 to 1998 ) and mid-October (1999 to 2002). ${ }^{3} \mathrm{MC}=$ chemical control in vine row, mechanical control in working row. 
appropriate soil management practice for young vineyards on sandy soils in the warmer climatic regions. This will enhance the development of the permanent structure of trellised grapevines, while maximizing the harvest. When the grapevines reached full production (fourth growing season, third season of the trial), the yield of the BB treatments in which grazing vetch, pink Seradella and 'Paraggio' medic were established, was superior to that of the grapevines in which the cover crops or weeds were mechanically incorporated into the top soil during bud break, as well as those in which the weeds were controlled chemically from just before bud break. Allowing the grain and Medicago species to complete their life cycle had a negative effect on grapevine performance both in the short and medium term (treatments applied for six consecutive years). Mechanical control of weeds and a grain cover crop from bud break or chemical control of weeds from just before bud break also impacted negatively on grapevine performance. The performance of full bearing grapevines established on a sandy soil was not affected negatively if the cover crops were controlled chemically during mid-October.

It should be possible to reduce the inorganic $\mathrm{N}$ applied after bud break on sandy soils in the warmer climatic regions in the short term (approximately after three years) or even stop the application in the medium term (after approximately five years) when using pink Seradella or grazing vetch with BB as soil management practice. Indications are that it may also be possible to reduce the inorganic $\mathrm{N}$ applied after bud break over the medium to long term with the BB treatments of the two Medicago species, as well as that of grazing vetch and pink Seradella controlled chemically during berry set. The impact that the cover crops have on the $\mathrm{N}$ status of the grapevines will depend on the performance of the cover crop. Pink Seradella and grazing vetch had a positive effect on the $\mathrm{N}$ concentration in the juice of the grapevines, irrespective of the soil management practice applied. A similar result could probably be achieved with the two Medicago species if they were controlled chemically before bud break.

Although the different soil management practices affected grape yield significantly over the 10 year period, they did not affect berry volume or wine quality.

\section{LITERATURE CITED}

Anonymous, 1984. Versuchergebnisse der staatlichen Weinbauinstitute. Rebe und Wein 4, 156-159. In: Sicher, L., Dorigoni, A. \& Stringari, G., 1995. Soil management effects on nutritional status and grapevine performance. Acta Horticulturae $383,73-82$.

Anonymous, 1997. Onkruide se weerstand teen middels wek kommer. Landbouweekblad 7 November, 95.

Archer, E. \& Booysen, J.H., 1987. Prieelstelsels vir wingerd. Wynboer Tegnies $21,3-14$

Buckerfield, J.C. \& Webster, K.A., 1996. Earthworms, mulching, soil moisture and grape yields. Wine Indust. J. 11, 47-53.

Champagnol, F., 1978. Fertilisation optimale de la vigne. Progrès Agricole et Viticole 95, 423-440.

Conradie, W.J., 1994. Wingerdbemesting. Handleiding van die werksessie oor wingerdbemesting, Nietvoorbij, 30 September, ARC Research Institute for Fruit, Vine and Wine, Private Bag X5026, Stellenbosch, 7600 RSA.

Conradie, W.J., 2001a. Timing of nitrogen fertilization and the effect of poultry manure on the performance of grapevines on sandy soil. I. Soil analysis, grape yield and vegetative growth. S. Afr. J. Enol. Vitic. 22, 53-59.

Conradie, W.J., 2001b. Timing of nitrogen fertilization and the effect of poultry manure on the performance of grapevines on sandy soil. II. Leaf analysis, juice analysis and wine quality. S. Afr. J. Enol. Vitic. 22, 60-68.

Conradie, W.J. \& Myburgh, P.A., 2000. Fertigation of Vitis vinifera L. cv. Bukkettraube/ 110 Richter on a sandy soil. S. Afr. J. Enol. Vitic. 21, 40-47.

Dupuch, V., 1997. Entretien des sols viticoles et conséquences oenologiques. Progrès Agricole et Viticole 114, 152-156. In: Horticultural Abstracts 68, 396.

Fourie, J.C., Louw, P.J.E. \& Agenbag, G.A., 2001. Effect of seeding date on the performance of grasses and broadleaf species evaluated for cover crop management in two winegrape regions of South Africa. S. Afr. J. Plant Soil 18, 118-127.

Fourie, J.C., Louw, P.J.E. \& Agenbag, G.A., 2005. Cover crop management in a Sauvignon blanc/Ramsey vineyard in the semi-arid Olifants River Valley, South Africa. 1. Effect of management practices on selected grass and broadleaf species. S. Afr. J. Enol. Vitic. 26, 131-139.

Fourie, J.C., Louw, P.J.E. \& Agenbag, G.A., 2006. Cover crop management in a Chardonnay/99 Richter vineyard in the Coastal wine grape region, South Africa. 2. Effect of different cover crops and cover crop management practices on grapevine performance. S. Afr. J. Enol. Vitic. 27, 42-50.

Henkes, R., 1997. Handling herbicide resistance. The furrow 102, 8-11.

Henschke, P.A. \& Jiranek, V., 1993. Yeasts-metabolism of nitrogen compounds. In: Fleet, G.H. (ed). Wine microbiology and biotechnology. Harwood Academic Publishers, Chur, Switzerland. pp. 77-164.

Hunter, J.J. \& Visser, J.H., 1990. The effect of partial defoliation on some growth characteristics of Vitis vinifera L. cv. Cabernet Sauvignon. II. Reproductive growth. S. Afr. J. Enol. Vitic. 11, 26-32.

Ingels, C.A., Scow, K.M., Whisson, D.A. \& Drenovski, R.E., 2005. Effects of cover crops on grapevines, yield, juice composition, soil microbial ecology, and gopher activity. Am. J. Enol. Vitic. 56, 19-29.

Jiranek, V., Langridge, P. \& Henschke, P.A., 1995. Amino acid and ammonium utilization by Saccharomyces cerevisiae wine yeasts from a chemically defined medium. Am. J. Enol. Vitic. 46, 75-83.

Lombard, P., Price, S., Wilson, W. \& Watson, B., 1988. Grass cover crops in vineyards. Proceedings Second International Cool climate Viticulture and Oenology Symposium, Auckland, New Zealand, January, 152-155.

Louw, P.J.E. \& Bennie, A.T.P., 1992. Water runoff and soil erosion in vineyard soils. Austr. Grapegrower \& Winemaker Annual Technical Issue, 100-113.

Maigre, D., 1997. Influence de l'enherbement et de la fumure, azotée sur la qualité des vins de Chasselas. Progrès Agricole et Viticole 114, 255-258. In: Hort. Abstr. 68,769

Ough, C.S., 1991. Influence of nitrogen compounds in grapes on ethyl carbamate formation in wines. In: Rantz, J.M. (ed.). Proc. International Symposium on Nitrogen in Grapes and Wine, 18-19 June, Seattle, Washington, USA. pp. 165-171.

Pinamonti, F., Stefanini, M. \& Dalpiaz, A., 1996. Soil management effects on nutritional status and grapevine performance. Vitic. Enol. Sci. 51, 76-82.

Pool, R.M., Dunst, R.M. \& Lakso, A.N., 1990. Comparison of sod, mulch, cultivation, and herbicide floor management practices for grape production in nonirrigated vineyards. J. Amer. Soc. Hort. Sci. 115, 872-877.

SAS, 1990. SAS/STAT users guide, version 8, first edition, volume 2. SAS Institute Inc., Campus drive, Cary NC 27513.

Shapiro, S.S. \& Wilk, M.B., 1965. An analyses of variance test for normality (complete samples). Biometrika 52, 591-611.

Shennan, C., 1992. Cover crops, nitrogen cycling, and soil properties in semiirrigated vegetable production systems. HortScience 27, 749-754.

Sicher, L., Dorigoni, A. \& Stringari, G., 1995. Soil management effects on nutritional status and grapevine performance. Acta Horticulturae 383, 73-82.

Smart, R.E., Dick, J.K., Gravett, I.M. \& Fisher, B.M., 1990. Canopy management to improve grape yield and quality - Principles and practices. S. Afr. J. Enol. Vitic. $11,3-17$.

Soil Classification Working Group, 1991. Soil classification - A taxonomic system for South Africa. Department of Agricultural Development: Memoirs on natural agricultural resources of South Africa No 15, Department of Agricultural Development, Pretoria, South Africa.

Soyer, P., Delas, J., Molot, C., Andral, P. \& Casteran, P., 1984. Techniques d'entretien du sol en vignoble bordelaise. Progr. Agric. Vitic. 101, 315-320. 
Tan, S. \& Crabtree, G.D., 1990. Competition between perennial ryegrass sod and 'Chardonnay' wine grapes for mineral nutrients. HortScience 25, 533-535.

The Non-Affiliated Soil Analysis Work Committee, 1990. Handbook of standard soil testing methods for advisory purposes. Soil Sci. Soc. South Africa, P.O. Box 30030, Sunnyside, Pretoria.

Tromp, A. \& Conradie, W.J., 1979. An effective scoring system for sensory evaluation of experimental wines. Am. J. Enol. Vitic. 30, 278-283.

Van Huyssteen, L., 1990. The effect of soil management and fertilization on grape composition and wine quality with special reference to South African conditions.
Proc. $7^{\text {th }}$ Australian Wine Industry Conference, 13-17 August, 1989, Adelaide, South Australia, 16-25.

Van Huyssteen, L., Van Zyl, J.L. \& Koen, A.P., 1984. The effect of cover crop management on soil conditions and weed control in a Colombar Vineyard in Oudtshoorn. S. Afr. J. Enol. Vitic. 5, 7-17.

Van Huyssteen, L. \& Weber, H.W., 1980. The effect of selected minimum and conventional tillage practices in vineyard cultivation on vine performance. S. Afr. J. Enol. Vitic. 1, 77-83.

Zeeman, A.S. \& Archer, E., 1981. Stokontwikkeling, wintersnoei en somerbehandeling. In: Burger \& Deist, J. (eds). Wingerdbou in Suid-Afrika. Nietvoorbij, Stellenbosch, South Africa. pp. 202-233. 